\title{
Article
}

http://dx.doi.org/10.11646/phytotaxa.238.2.3

\section{Plant taxonomic capacity in South Africa}

\author{
JANINE E. VICTOR ${ }^{1,2^{*}}$, GIDEON F. SMITH ${ }^{3,4}$, SHANELLE RIBEIRO ${ }^{1} \&$ ABRAHAM E. VAN WYK $^{2}$ \\ ${ }^{1}$ Biosystematics Research \& Biodiversity Collections, SANBI, Private Bag X101, Pretoria, 0001 South Africa \\ ${ }^{2}$ H. G.W.J. Schweickerdt Herbarium, Department of Plant Science, University of Pretoria, Pretoria, 0002 South Africa \\ ${ }^{3}$ Department of Botany, P.O. Box 77000, Nelson Mandela Metropolitan University, Port Elizabeth, 6031 South Africa \\ ${ }^{4}$ Centre for Functional Ecology, Departamento de Ciências da Vida, Universidade de Coimbra, 3001-455 Coimbra, Portugal \\ *Author for correspondence.E-mail: J.Victor@sanbi.org.za
}

\begin{abstract}
South Africa's exceptionally rich and diverse flora faces challenges in terms of utilisation, management and conservation; these actions are underpinned by taxonomic research. The principal purpose of this review is to determine whether South Africa has the human capacity and resources to conduct taxonomic research that is required to support end-users of plant taxonomic information, and to identify shortages of capacity or resources that might prove to be an obstacle for plant taxonomic research. From an analysis of the existing gaps in taxonomic information, current research trends, and resources, it is apparent that there is a critical shortage of human capacity in South Africa to conduct plant taxonomic research for the benefit of biodiversity and society. Training institutions need to ensure the supply of suitably trained graduates including concentrating on those who meet Employment Equity targets. The need for more taxonomists is clearly justified, but may not be a priority in a country that already has such shortages of capacity in education and social services. Aside from lobbying for more jobs to be created, there is an urgent need to utilise available resources (human and other) effectively, and to implement a strategy for taxonomic research to ensure that priority activities are conducted.
\end{abstract}

Key words: biodiversity, megadiverse, herbarium, systematics, taxonomists, training, university

\section{Introduction}

South Africa is a megadiverse country with more than 20000 species and infraspecific taxa of vascular plants and bryophytes (Germishuizen et al.2006). This exceptionally rich and diverse flora faces challenges in terms of management and conservation. Careful planning, sufficient human capacity and financial resources, and efficient use of these are required to ensure that the demands of management and conservation are appropriately and comprehensively met. This review focuses on assessing the current (as of December 2014) capacity in South Africa for conducting taxonomic research on plants of the country, to determine whether there are sufficient resources in terms of: (1) human capacity, (2) research material and (3) financial or other resources, to conduct taxonomic research that is required to support the generation and dissemination of plant taxonomic information to end-users, and to identify shortages that might prove to be an obstacle in implementing a taxonomic research strategy in the future. In this review the term taxonomy is used as synonymous with systematics, to refer not only to the study of classification, but also the investigation of the causes and processes of evolution and the study of phylogeny.

The most recent comprehensive assessment of the state of taxonomy in South Africa was initiated by the South African National Committee for the International Union of Biological Sciences in 1979. The resulting report (Du Plessis 1985 ) concluded that the state of taxonomy was 'gloomy', and deteriorating. It was recommended that an effort be made to stimulate plant taxonomy, which led to the formation of a National (Stimulation) Programme for Plant Systematics along with the Working Group for Plant Systematics within then the Foundation for Research and Development, now the National Research Foundation (NRF). This working group arranged a variety of activities to promote and stimulate plant taxonomy in the country. From 1988 to 1996, 18 training workshops, five symposia and five joint interinstitutional collecting trips were conducted (Smith et al. 1996). Following these activities, South African botanists and colleagues from nine other southern African countries established the Southern African Botanical Diversity Network (SABONET) project in 1996, funded by the Global Environment Facility-United Nations Development Programme. 
This project had, as a primary aim, improving the human resource capacity and infrastructure of herbaria in southern Africa (Smith \& Willis 1997), strengthening and developing botany in southern Africa through workshops, courses and plant collecting expeditions. Reviews of the project concluded that SABONET had been very successful in attaining its goals of building capacity through training, purchase of equipment, digitisation of plant specimens preserved in herbaria, production of informative literature and creation of Red Lists throughout the countries involved.

\section{Plant taxonomists in South Africa}

Most of the expertise in plant taxonomy in South Africa is concentrated at the South African National Biodiversity Institute (SANBI) and at universities that offer taxonomy in the curriculum. There are approximately 35 professional plant taxonomists employed in academic posts as researchers and/or lecturers in South Africa, 19 of whom are with SANBI, and 16 at universities (see Tables 1 and 2). In addition to taxonomic researchers, there are many trained taxonomists employed as herbarium curators or technical support staff, both at SANBI and at universities; at least five of these staff members conduct research as well. At SANBI, managers have also made a significant contribution to taxonomic research, as most managers were career scientists before assuming management roles.

TABLE 1. Universities of South Africa (excluding universities of technology) and academic (teaching) staff that do research in plant taxonomy as at December 2014. Universities of technology are excluded as none of them employ plant taxonomists or offer taxonomic training. $\mathrm{W}=$ White; $\mathrm{F}=$ Female; $\mathrm{M}=$ Male; $\mathrm{B}=$ Black

\begin{tabular}{|c|c|c|c|c|}
\hline \multirow[t]{2}{*}{ University } & \multirow[t]{2}{*}{ Herbarium } & \multicolumn{2}{|c|}{$\begin{array}{l}\text { Academic staff (including } \\
\text { curators that also lecture) }\end{array}$} & \multirow{2}{*}{$\begin{array}{l}\text { Capacity for } \\
\text { postgraduate training } \\
\text { in taxonomy }\end{array}$} \\
\hline & & Number & $\begin{array}{l}\text { Population } \\
\text { group }\end{array}$ & \\
\hline University of KwaZulu-Natal & $\begin{array}{l}\text { Pietermaritzburg: Bews (NU) } \\
\text { Westville: Ward (UDW) }\end{array}$ & 3 & $3 \times \mathrm{WM}$ & Yes \\
\hline Rhodes University & Selmar Schonland (GRA) & 1 & WM & Yes \\
\hline University of Cape Town & Bolus (BOL) & 2 & $\begin{array}{l}\text { WM } \\
\text { BM }\end{array}$ & Yes \\
\hline University of Pretoria & H.G.W.J. Schweickerdt (PRU) & 1 & WM & Yes \\
\hline University of the Western Cape & University of the Western Cape (UWC) & 1 & WM & Yes \\
\hline University of the Free State & Geo-Potts (BLFU) & 1 & WF & Yes \\
\hline North-West University & AP Goossens (UNWH) & 1 & WM & Yes \\
\hline University of Johannesburg & University of Johannesburg (JRAU) & 2 & $\begin{array}{l}\text { WM } \\
\mathrm{BF}\end{array}$ & Yes \\
\hline $\begin{array}{l}\text { University of the } \\
\text { Witswatersrand }\end{array}$ & CE Moss (J) & 2 & $\begin{array}{l}\text { WM } \\
\text { WF }\end{array}$ & Yes \\
\hline University of Limpopo & Larry Leach (UNIN) & 0 & 0 & No \\
\hline University of Zululand & University of Zululand (ZULU) & 0 & 0 & No \\
\hline Stellenbosch University & Stellenbosch University (STEU) & 1 & WF & Yes \\
\hline $\begin{array}{l}\text { Nelson Mandela Metropolitan } \\
\text { University }\end{array}$ & Ria Olivier (PEU) & 0 & 0 & No \\
\hline University of Fort Hare & Giffen (UFH) & 0 & 0 & No \\
\hline University of Venda & none & 0 & 0 & No \\
\hline Walter Sisulu University & Walter Sisulu University (KEI) & 1 & WF & Yes \\
\hline University of South Africa & Unregistered herbarium & 0 & 0 & No \\
\hline
\end{tabular}


TABLE 2. Taxonomic researchers employed at SANBI (as at December 2014). W=White; B=Black; F=Female; M=Male.

\begin{tabular}{lllll}
\hline Herbarium & Researchers & & Ph.D.s & Population group \\
\hline Number & Population group & Number & P WF; 2 WM \\
National Herbarium (PRE) & 15 & $1 \mathrm{WF} ; 2 \mathrm{WM}$ & 3 & $2 \mathrm{WF} ; 1 \mathrm{WM}$ \\
KwaZulu-Natal Herbarium (NH) & 1 & $4 \mathrm{WM} ; 5 \mathrm{WF} ; 6 \mathrm{BF}$ & 4 & \\
\hline
\end{tabular}

There is an unequal distribution of plant taxonomic researchers at universities, for example in December 2014 there were three lecturers employed in the field of taxonomy at the University of KwaZulu-Natal, whereas six universities in South Africa had no plant taxonomists in academic posts as researchers and lecturers. Of greater concern is that very few full time students study taxonomy at postgraduate level at universities. Most of those that do qualify in taxonomy emphasise phylogenetics, and not traditional alpha-taxonomy, in their studies. Although most have found employment as taxonomists, the persisting perception that there are few employment opportunities for graduates in the field of plant taxonomy may be a deterrent to students choosing taxonomy as a career. There are numerous complex social aspects influencing the path of a student to becoming a professional taxonomist. Such factors include the competence of teachers of botany and taxonomy; their ability to attract students to taxonomic research programmes that will lead to postgraduate specialisation in taxonomy; and the provision of postdoctoral research fellowships to retain investment into taxonomy graduates. An in depth analysis of these aspects at each university over a number of years could provide further insight into the deficiency of training taxonomists in South Africa.

In addition to the currently employed taxonomists in South Africa, there are at least nine professionals who are not employed as plant taxonomists but conduct plant taxonomic research, as indicated by taxonomic research published in peer-reviewed journals in the five years preceding December 2014. A very important contribution to taxonomic research is made by retired professionals, of which the number actively contributing in the past five years, to December 2014, is six from universities and seven from SANBI.

Three SANBI plant taxonomists, and two based at universities, will retire from formal employment within the next five years. More than half of the plant taxonomists in the workforce are under the age of 50, which means that there should not be a sudden drop in capacity of plant taxonomists in the short to medium term. The main obstacle to maintaining or increasing capacity at SANBI and other government-funded institutions such as universities and museums, is the Employment Equity Act, number 55 of 1998 which discourages recruitment of researchers from the white population group. In the past five years, six plant taxonomist posts have been advertised at SANBI's three herbaria, and it was possible to fill only two of these with candidates meeting Employment Equity targets. Posts had to be re-advertised, sometimes on multiple occasions, due to the lack of qualified candidates meeting Employment Equity targets. As a result, two of these posts were not filled and one was filled with a candidate who did not meet Employment Equity targets.

\section{Current state of taxonomic research}

The current state of taxonomic research on South African plants can be ascertained in terms of the availability of up to date literature for all species; trends in taxonomic research in South Africa; and productivity of South African plant taxonomic researchers.

\section{Progress with taxonomic treatments of South African plants}

The main sources of information for plants are family treatments, Floras for geographically delimited areas, and taxonomic revisions of genera. For species level information, various internet web pages frequently provide information on species, particularly if they are of horticultural or economic value. While classic revisions and, to a lesser extent, Floras consist of complete species descriptions and geographical distribution (and sometimes habitat) information, web pages tend to offer additional information on plants such as how to grow them or their medicinal uses.

The Flora of southern Africa (FSA) project was initiated in 1955 aiming to document more than 20000 species of 180 angiosperm families in South Africa, Botswana, Lesotho, Swaziland and Namibia over a period of 40 years. Progress with the FSA project was not as rapid as expected, and after 40 years only about $18 \%$ of the species had been treated. A decision to de-emphasise the FSA in favour of publishing manuscripts in an in-house journal of SANBI, 
Bothalia, under the banner of 'FSA contributions' was taken in 1995. Although the FSA project does not currently exist as a formal project, volumes may still be published in future.

There are approximately 931 currently recognised genera of indigenous vascular plant species in South Africa. Revisions of taxonomic groups are scattered throughout various national (e.g. Bothalia and South African Journal of Botany) and international (e.g. Opera Botanica and Kew Bulletin) journals. A survey of all taxonomic revisions for South African plant genera reveals that there are 50 genera that were last revised prior to 1900. Revisions published prior to 1900 are, as one would expect, mostly outdated. This is because new species have since been discovered and existing taxonomic concepts have changed as more information becomes available, which in turn leads to better understanding of demarcations between and relationships among species. Also, an additional 100+ years of fieldwork have resulted in more comprehensive habitat and distribution information becoming available, for example from herbarium specimens and natural history observations.

Apart from Flora treatments and taxonomic revisions, additional major sources of taxonomic information for South and southern Africa have been published in SANBI's in-house journal, Strelitzia. A series of in-country regional Floras for South Africa have been published, or are still in progress, with the eventual aim of providing a floristic coverage of the whole country. Floras for the northern provinces (comprising Gauteng, Limpopo, Mpumalanga and North-West and covering over 5700 species) and the 'Greater Cape Floristic region' covering Western Cape and parts of the Northern and Eastern Cape ('Core Cape Subregion' covering approximately 9200 species and 'Greater Cape Subregion' covering about 3700 species) have recently been published (Retief \& Herman, 1997; Manning \& Goldblatt 2013; Snijman 2013); and those for the Free State (almost 3000 species) and Eastern Cape (over 7300 species) have been completed and are being processed for publication. A volume on the remaining parts of the Northern Cape not treated in the Plants of the Greater Cape Floristic Region is in preparation, covering an estimated 3200 species, and will be submitted for publication in 2016. Completion of a Flora of KwaZulu-Natal would result in regional treatments covering the flora of the entire country (Victor et al. 2013).

\section{Trends in taxonomic research}

The number of new species and infraspecific taxa of South African plants described per year over the past 34 years was investigated to determine the research output productivity of taxonomists in South Africa, and thus their capacity to undertake and publish research. This provides an indication of how much new information is still being discovered, and from this it should be possible to extrapolate to predict whether there is still more to be discovered. The capacity for taxonomic research to be conducted by South African taxonomists is also reflected in the contributions by South African taxonomists relative to non-South African taxonomists.

There is no definite trend in the number of plant taxa described per year over the past 34 years (Fig. 1). Numerous factors contribute to year-to-year variations and it would be mere speculation to attempt to explain these. For example, the slight reduction in the number of species described by South African botanists from 1991 to 1994 could be attributed to the time when the majority of SANBI taxonomists, and some university collaborators, were engaged with compilation of the comprehensive plant species checklist of South Africa (Arnold \& De Wet 1993). The only other year in which fewer than 20 new taxa were described was in 2008, but no obvious reason for this is discernible. The timing of the drop in number of new species described in revisions correlates with the establishment of the Leslie Hill Molecular Laboratory at the Kirstenbosch Research Centre in 2002, and the emphasis placed by SANBI research managers on conducting phylogenetic (mainly macrotaxonomic) research utilising molecular techniques. Another aspect of the description of new taxa that is worth noting is that in the 1980s (1980 to 1989), 102 (14\% of the total) taxa described were infraspecific taxa; in the 1990s, 57 (8\%) were infraspecific taxa; and between 2000 and 2009, 72 $(11 \%)$ were infraspecific taxa.

There is an apparent increase in number of taxa described in stand-alone (i.e. not part of a taxonomic treatment of a genus or family) scientific papers from 1995 onwards both by national and international scientists, with consistently fewer than 20 new taxa per year being described before 1995 and consistently more than 20 taxa being described each year from 1995 onwards. There is a corresponding reduction in the number of species described in taxonomic treatments (mainly generic revisions) of groups from 2002. The effect of publishing more individual species descriptions and fewer taxonomic treatments of groups would be an increased output of number of papers by scientists. The timing of this increase in numbers of stand-alone papers describing species correlates with the increasing tendency towards measuring productivity in terms of output of number of papers after the introduction of Corporate Strategic Plans at SANBI in 1991, and at universities, the measurement of academic productivity became increasingly, at least to some degree, based on number of papers, as were the formulae for funding research. 


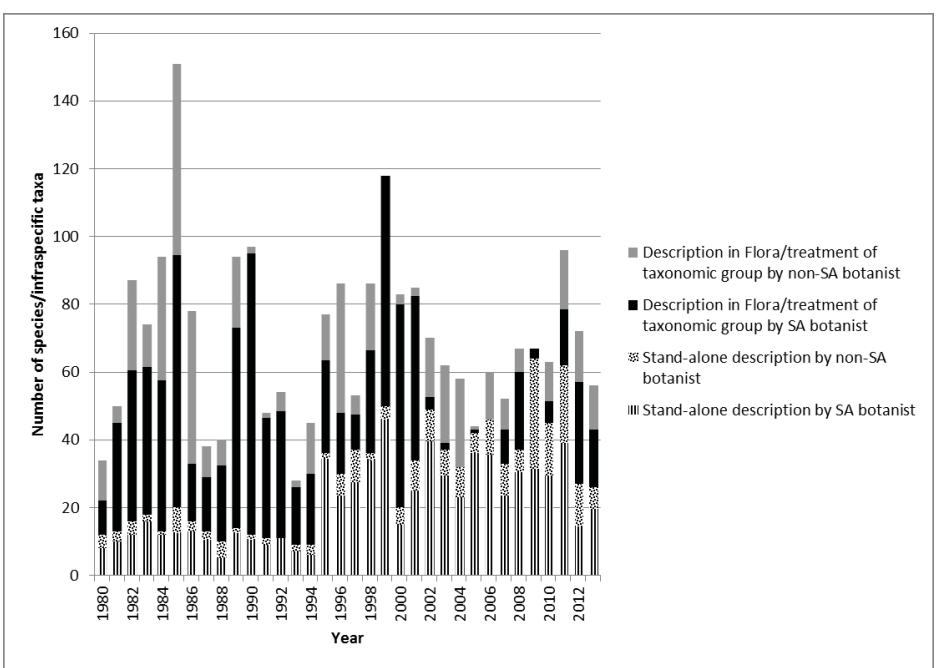

FIGURE 1. Number of plant taxa in South Africa described per year from 1980 to 2013 by South African (SA) and non-South African (non-SA) botanists, in revisions or as stand-alone papers.

Opportunistic discoveries of new species in the field account for a small proportion of all taxa described, e.g. Callilepis corymbosa Herman \& Koekemoer (2014: 254) discovered during the course of general fieldwork. Its recognition as a new species happened when the specialist in this group was unable to satisfactorily determine its identity in the herbarium. However, most new taxa are discovered in the course of revisions, when examining existing and often unnamed specimens in herbaria, for example Kupicha (1984) described 10 new taxa in her revision of the genus Schizoglossum Meyer (1837: 218). In addition, a large number of the stand-alone taxon descriptions that have appeared recently resulted from discoveries made in the course of curatorial herbarium work (doing identifications and working through collections), but were published separately rather than as part of a revision. The genus Ixia Linnaeus (1753: 36) a member of the Iridaceae family with 68 taxa indigenous to South Africa, makes an interesting case study to illustrate this. Ixia was first treated as a genus in Flora capensis (Baker 1896), and later revised by Lewis (1962) with 32 new taxa described. De Vos (1999) conducted the next revision of the genus for the Iridaceae contribution to the FSA project, adding two new varieties. Between 1993 and 2015, 39 new taxa of Ixia were published, of which eight species were published in seven stand-alone papers (Goldblatt \& Manning 1993, 1999, 2004, 2010, 2012b; Goldblatt et al. 2015; Manning \& Goldblatt 2006). The stand-alone papers describing new taxa of Ixia are sometimes published with additional taxonomic notes on other members of the Iridaceae, and other new species descriptions. In addition, three revisions covering four sections of Ixia were published in three different papers (Goldblatt \& Manning $2008,2011 \& 2012 a)$, with a total of 29 new taxa described. The advantage of describing new species as they become available rather than as part of a comprehensive revision is that the information is then immediately available for use by end-users, especially conservation planners for example; the disadvantage is that the information is fragmented throughout the literature rather than being available in one consolidated source.

It is challenging to estimate what proportion of the flora of South Africa is currently undescribed, because of the variability in proportion of new species uncovered per genus during revisions conducted over the past 35 years. Revisions of relatively large genera (more than about 15 species) of small plants (small shrubs, succulents, geophytes, and herbs) since 1980 have elucidated numerous new species (excluding those that have been re-instated and those that have subsequently been taken into synonymy). Since 1993, 57\% (39) more taxa (species and infraspecific taxa) of Ixia have been described, which suggests that the potential for discovering more during revisions of plant genera is very high. In the 1970s revisions were conducted in genera of the subtribe Diosminae of the Rutaceae, which are characteristically sclerophyllous dwarf shrubs. Within this group, 7\% (2) more taxa of Diosma Linnaeus (1753: 198) were described; 15\% (5) more Acmadenia Bartling \& Wendland (1824: 59); and 52\% (12) more Euchaetis Bartling \& Wendland (1824: 15). In contrast, no new species of the local tree genera in the family have been described for over 50 years. From personal experience in the Rutaceae it is believed that only the genus Agathosma Willdenow (1809: 259) (135 taxa), last revised in 1950, harbours yet undescribed species. It is estimated that a revision of Agathosma should reveal at least $10 \%$, but probably closer to $20 \%$, more species than is currently known. In the geophytic Iridaceae, 39\% (14) more Dierama Koch (1854: 10) infrageneric taxa have been described since 1980; 16\% (27) more Gladiolus Linnaeus (1753: 36) and 46\% (47) more Geissorhiza Ker Gawler (1803: 672). According to John C. Manning (personal 
communication, 2015), there are now only four currently known new species of Iridaceae in South Africa awaiting publication, and it is unlikely that many more will be discovered.

The conclusion that can be drawn from these estimates is that there are likely to be on average about $20 \%$ of new species in South African plant genera that have not been revised since 1980, particularly those with a predominantly small habit. It is unlikely that further study of recently revised genera would yield large proportions of undescribed species. Therefore, of the approximately 5500 species in South Africa not revised since 1980 (according to survey of the literature), there are probably about 1100 species (at a rate of $20 \%$ undescribed) yet unknown to science. This equates to about $5 \%$ of the current known flora of South Africa.

\section{Publication output by taxonomists}

For the following analysis of publication outputs of taxonomists, only numerical results are provided. Data were collected mostly from personal communication, but in some cases where available, information was obtained from websites. Where no information was available for a researcher, or if employment term had been less than two years, the analysis excluded those researchers.

During a total of 153 person years worked between 2000 and 2014, 15 university-based taxonomists (as of December 2014) published 779 papers. Of these, 131 (16.8\%) were first-authored, or very rarely, sole-authored, publications. Whereas the average number of papers per year is 5.1 per person, of these, the average number of first-authored papers per year is 0.86 per person. During 171 person years of totalled employment, 17 of the SANBI taxonomists published 431 papers, of which 242 (or 56\%) were first-authored. Therefore the average number of papers per year for SANBI staff members is 2.5 papers per person, of which 1.4 papers per person are first-authored. A direct comparison between the total number of papers published per person at SANBI and the universities would not give an accurate measure of relative productivity, because of the large number of duplications of counting due to the large numbers of co-authors from multiple institutions, especially for papers published by university-based taxonomists. The only truly reflective comparison available is therefore the number of first-authored papers.

A review of the titles of the papers published by taxonomists at both universities and SANBI show that the subject matter is very variable, and not limited to plant taxonomy, particularly in the case of university-based taxonomists. Where authors are not the sole or first author of a paper, the subject matter is usually not within that researcher's area of primary expertise, and particularly at universities, these papers are frequently (e.g. $50 \%$ of the papers of one author) not in plant taxonomy but in related (e.g. ecology) or sometimes very unrelated fields such as microbiology, chemistry, soil analysis, and zoology. Furthermore, co-authored articles are published in a variety of journals seemingly unrelated to plant taxonomy e.g. Nuclear Instruments and Methods in Physics Research; Journal of the South African Veterinary Association; Forensic Science International and Journal of Fish Biology.

An analysis was conducted by the Threatened Species Programme of SANBI to determine what proportion of South Africa's flora has been revised recently enough to provide sufficient information for conservation assessments (Von Staden et al. 2013). This analysis shows that $54 \%$ of the South African flora had been treated in generic or family taxonomic treatments published between 1970 and 2011. During this time most treatments were published in the 1980s and 1990s, with a significant decline in the last decade of the analysis. A reduction in generic or family taxonomic treatments between 2002 and 2011 can be inferred from the data presented in Fig. 1, but this can not necessarily be attributed to a lower productivity of taxonomists considering the marked increase in the number of species described in stand-alone publications. This decade (2000-2010) also corresponds with an increase in numbers of papers in molecular phylogeny being published, leading to changes at the suprageneric (or macrotaxonomic) level owing to greater understanding of evolutionary relationships. Increasing numbers of modern revisions also include a phylogeny to circumscribe the group of interest, identify nearest relatives, and identify patterns of character evolution.

Peer-reviewed publications remain an important yardstick for measuring productivity of taxonomists. However, some of the most important products to end-users often include those that are published in other forms. Among the more important local products is the checklist of South African plants, which has been published in hard copy e.g. Arnold \& De Wet (1993), and subsequently Germishuizen et al. (2006) and is available online under the title Plants of Southern Africa (POSA) on the SANBI website (http://posa.sanbi.org/searchspp.php). Another critical product is the Brahms database (previously National Herbarium, Pretoria [PRE] Computerised Information System [PRECIS]) of specimen information and dissemination of this online. In addition, certain products generated predominantly by SANBI taxonomists, some with valuable contributions from university-based taxonomists, have been very popular, 
e.g. Seedplants of southern Africa: families and genera (Leistner 2000), Herbarium essentials (Victor et al. 2004), Guide to the plant families of southern Africa (Koekemoer et al.2015), Plants of the Greater Cape Floristic Region 1: the Core Cape flora (Manning \& Goldblatt 2013) and Plants of the Greater Cape Floristic Region 2: the Extra Cape flora (Snijman 2013). University taxonomists produce books to a lesser extent, but notable are publications such as Medicinal plants of South Africa (Van Wyk et al. 2009), Field guide to trees of southern Africa (Van Wyk \& Van Wyk 2013) and Field guide to the wild flowers of the Highveld (Van Wyk \& Malan 1997).

A discussion forum was held by SANBI staff members (D. Raimondo in collaboration with L. Von Staden, M. Hamer and J.E. Victor) at the Southern African Society for Systematic Biology conference in Arniston, July 2012, to determine ways to stimulate the production of taxonomic revisions. The participants were asked what obstacles prevented them from carrying out taxonomic revisions, and answers are summarised as follows:

a) There is a perception that the academic merit system and funding allocation at South African universities inadvertently discourage publication of revisions as they are time consuming to conclude and thus reduce publication output. Shorter taxonomic publications which lead to a higher number of papers are therefore favoured. Criteria for career advancement and promotion take into account the impact factor of journals in which papers are published, and the citation record for papers published. Because taxonomic journals tend to have lower impact factor and revisions are not cited often, publishing only descriptive revisions can have a negative impact on these criteria (Krell 2002).

b) There are limited opportunities for students to study traditional taxonomy at universities where the focus of taxonomic research projects is more on phylogenetic studies than revisions, especially considering that it often takes less time to complete such investigations and publish results. Phylogenetic studies can be published in higher impact factor journals and receive higher citation ratings. Therefore, taxonomic research is mostly carried out by more experienced researchers with accumulated knowledge of the groups in which they specialise.

c) Lack of information about research priorities was regarded as an obstacle to doing taxonomic revisionary work. The need for an integrated source of information on what taxonomic research has been done, who is busy with what research projects, and what the priorities are for further research, was emphasised.

In further discussions during the workshop, it was suggested that funding should be directed towards projects that would contribute towards specific priority research targets, rather than putting out general calls for applications where researchers can choose their group of study.

\section{Availability of research material from South African herbaria}

Herbaria are indispensable resources for taxonomic research. South Africa has at least 72 herbaria, housing more than 3.2 million plant specimens, which is less than $1 \%$ of the world's 350 million (Thiers, continuously updated) plant specimens. In South Africa, $80 \%$ of preserved plant specimens are housed in the eight largest herbaria (Table 3) (Smith \& Willis 1999). Most of these herbaria were established between 1970 and 1990. Between 1970 and 1980, 17 new herbaria were founded in South Africa, and 13 more up to 1990. In contrast, in the decade before 1970 only nine new herbaria were established, and eight in the decade after 1990. Very few were established at any time before or after this 50 year period (Smith \& Willis 1999). The top 10 herbaria and the numbers of specimens they contain is shown in Table 3, and for all other herbaria in South Africa there is a comprehensive review for the southern African region (Smith \& Willis 1999). Each of the other herbaria in South Africa has fewer than 25000 specimens.

Although there are a large number of specimens in herbaria around South Africa, the representation of specimens geographically is unequally distributed. Fig. 2 shows that there are certain parts of the interior of the country that are represented by fewer than 10 specimens per quarter degree grid square (representing roughly $25 \times 25 \mathrm{~km}$, or 625 $\mathrm{km}^{2}$ ). In many cases this can be attributed partly to lower levels of diversity but even if this is the case, the number of specimens should be higher than 10 per quarter degree grid to be representative of the flora for the area. One of the main reasons for the lack of collections from certain grids is poor accessibility, the bulk of the existing herbarium collections being from near major roads. Privately-owned farms in the arid interior of the country tend to be quite large and because a deliberate attempt must be made to survey them floristically, relatively few have been visited by plant collectors. The poor collecting record for parts of the northern Free State and central parts of North-West is in part due to extensive transformation of the natural vegetation by agronomy (this area is part of the so-called 'maize triangle'). SANBI, then as the NBI, had a National Plant Collecting Programme to improve regional coverage of South Africa in terms of plant specimens, and free identifications (whereas a handling fee is charged for all other collections) were provided to non-SANBI collectors who submitted good quality specimens for donation to SANBI and that targeted under-represented areas. The advantage was that amateur botanists ('parataxonomists') could contribute herbarium 
specimens to the collections. However, in practice, amateur botanists did not specifically target areas identified as 'under-collected', and therefore specimens submitted from collectors were not always from under-represented areas. For this reason the programme was not as effective as anticipated. According to the current coverage of specimens shown in Fig. 2, there is still much to be done to fill the gaps in data. Although no longer a formal programme, SANBI still offers an informal service to have collections identified for free for collectors who apply and meet the requirements (i.e. donating good quality, fertile specimens from priority areas to SANBI), and this is evaluated on a case by case basis. More strategic identification of important areas to target for expanding herbarium specimen holdings, for example areas earmarked for development, may be an efficient way of improving coverage of underrepresented areas.

TABLE 3. Number of herbarium specimens in the 10 largest herbaria in South Africa.

\begin{tabular}{lll}
\hline Herbarium & Acronym & Number of specimens \\
\hline National Herbarium, SANBI & PRE & 1200000 \\
Compton Herbarium (incorporating SAM \& STE), SANBI & NBG & 500000 \\
Bolus Herbarium, University of Cape Town & BOL & 300000 \\
Selmar Schönland Herbarium, Albany Museum & GRA & 200000 \\
Bews Herbarium, University of KwaZulu-Natal & NU & 120000 \\
H.G.W.J. Schweickerdt Herbarium, University of Pretoria & PRU & 110000 \\
Charles E. Moss herbarium, University of the Witwatersrand & J & 100000 \\
KwaZulu-Natal Herbarium, SANBI & NH & 100000 \\
Kimberley Herbarium, McGregor Museum & KMG & 32600 \\
Bloemfontein Herbarium, National Museum & NMB & 25000 \\
\hline
\end{tabular}

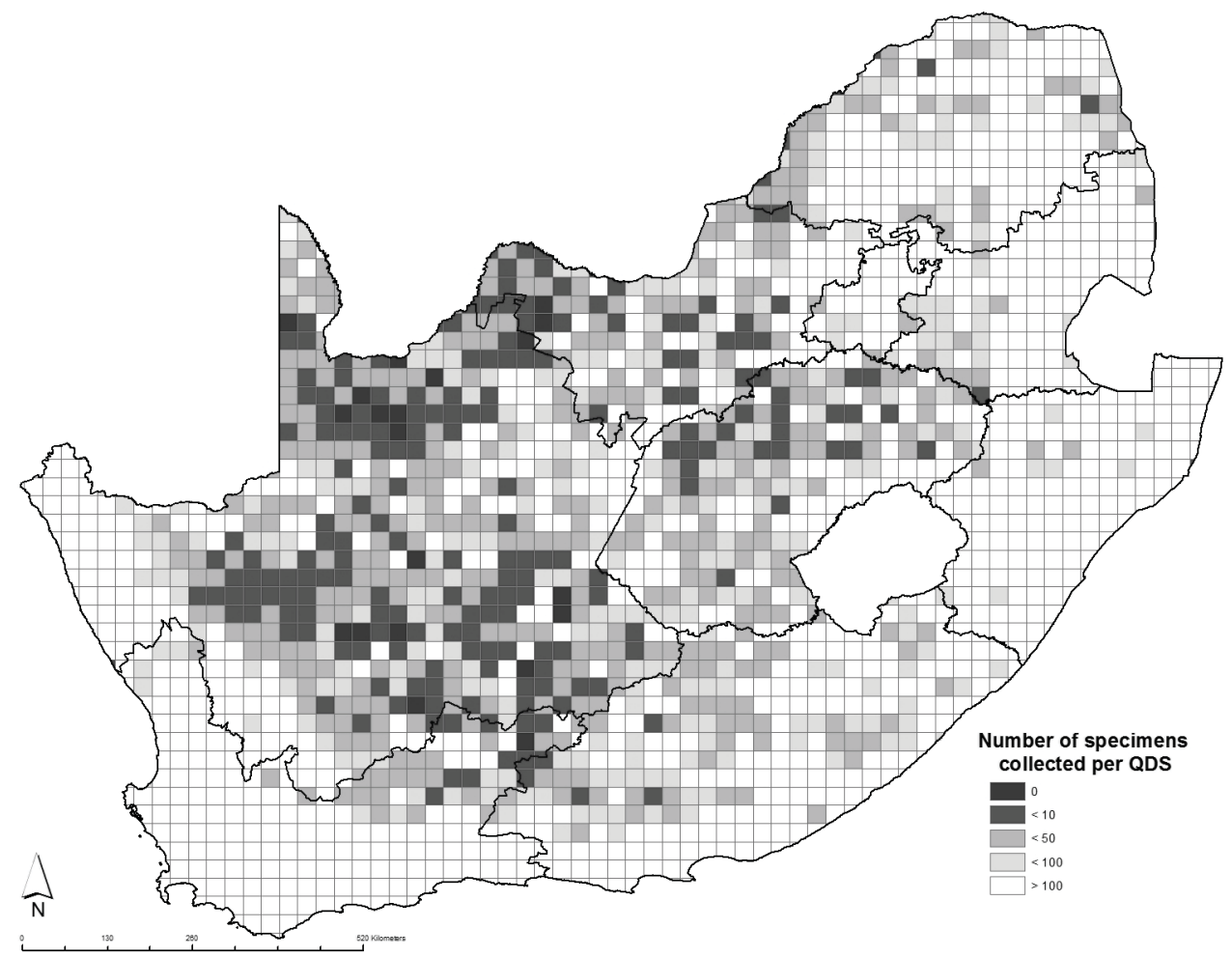

FIGURE 2. Map of South Africa showing the collecting intensity for South Africa, as reflected by the Brahms database of specimens in SANBI herbaria. QDS = quarter degree square. Source: Biodiversity Information Management \& Planning, SANBI. 
In SANBI herbaria there are more than 3800 taxa that are represented by five or fewer specimens. This is an indication of how representative of the South African flora the herbarium collections are. The most under-represented family in this respect is the predominantly succulent Aizoaceae (s.l.), which has the highest number of genera with fewer than five specimens per taxon (see Chesselet et al. 1995). Taxa represented by few specimens are characteristically rare and often distributed in inaccessible or hard to access localities. Another reason for lack of specimens is that some are awkward to collect and press due to for example the size or degree of succulence or spinescence of the plants. Collecting to specifically target these taxa would provide vital foundational information not only for taxonomic purposes, but also for providing information for end-users, e.g. conservationists.

Only 6276 herbarium specimens (out of a current total of about 1.8 million specimens in SANBI herbaria) collected in South Africa by early explorers before 1850 are presently in SANBI herbaria, after which the number of collectors and collections in South African herbaria accelerated rapidly as the interior of the country became more accessible and increasingly populated. Improvement of rail and road transport infrastructure resulted in the intensified botanical exploration of the country, eventually peaking in 1976 according to specimen accession records of SANBI's herbaria. In the decade 1975 to 1985 , more specimens were collected and lodged in SANBI herbaria than in any other decade and since then numbers have dropped steadily for various reasons. Reasons that can be attributed to the decline in number of specimens collected as represented in SANBI herbaria include, inter alia, the introduction of handling fees for identification of plant specimens at the end of the 1980s; increased security risks, and subsequent reduced and more strictly controlled access to land from owners; increasingly onerous permitting requirements for plant collecting; increasing costs of fieldtrips; and reduced personal safety of carrying out fieldwork. In addition, the establishment of 17 new herbaria between 1970 and 1990 may have had an impact by attracting some specimens that otherwise would have populated SANBI herbaria.

\section{Financial resources}

A survey of opinions amongst South African botanical researchers (Bredenkamp \& Smith 2008) revealed that twothirds of respondents regarded inadequate funding as a 'significant impediment to progress in botanical research.' However, SANBI and universities provide funding for research, and there is currently no obstacle to research at SANBI due to inadequate funding although this is subject to change depending on government budget allocations. Vehicles are available for fieldwork at SANBI and some universities, although research grants are used to hire vehicles when appropriate. Most universities have laboratories with facilities for conducting molecular analyses, as well as specialised equipment such as scanning electron microscopes, and SANBI staff frequently work in collaboration with university staff members to make use of these facilities. In addition, SANBI herbaria and universities provide access to libraries and inter-library loans, and have subscribed to JSTOR Global Plants, and there is therefore no shortage of access to 'old' and current literature. Additionally, access to older literature has been made considerably easier with the availability of open access online facilities such as the Biodiversity Heritage Library, Botanicus, and the Digital Library of the Spanish Royal Botanic Garden. All SANBI and university taxonomists have personal, often networksupported, computers and access to the internet.

A comprehensive needs assessment that was conducted for southern African herbaria (Smith et al. 1999) as part of the SABONET project revealed that herbaria in the region had a shortage of dissecting and compound microscopes, computers and herbarium cabinets. These items comprised the majority of the capital item budget expenditure that was required at the time. At present the majority of taxonomists at SANBI and universities of South Africa do not have a shortage of these items. This positive development may indicate that budget allocation at the various institutions was indeed influenced by the report.

At SANBI, taxonomic researchers have access to a limited amount of governmental funds that cover some costs of research. This is usually sufficient to cover most running costs of research projects (e.g. fieldwork or specialised microscopy services), but staff members are encouraged to source additional funds from funding agencies so that the budget can stretch further. As a result of many successful applications to funding agencies, taxonomists at SANBI are able to conduct taxonomic work with sufficient financial resources available to them.

Funding for South African taxonomic research is provided by the Department of Science and Technology (DST) via the NRF. In 2002 the DST established a South African Biosystematics Initiative (SABI) to enhance taxonomic research of all organisms in South Africa. SABI was established following the compilation of a report (Herbert et al. 2001) that pointed out dire challenges faced by taxonomy and collections in South Africa. Between 2005 and 2012, about R96 million has been invested by the DST in South African taxonomy (not only plants but also other organisms), 
and in particular research projects with a phylogenetic/molecular component. There are few additional sources of local funding mainly aimed at promoting taxonomic research, for example the Botanical Education Trust, which operates under the auspices of the KwaZulu-Natal branch of the Botanical Society of South Africa (http://www.botsoc-kzn.org. $\mathrm{za} / \mathrm{html} /$ botanical_education_trust.html).

\section{Discussion and conclusions}

From this review we can conclude that there is a severe shortage of capacity available to manage the country's rich and diverse flora in terms of taxonomy and provision of foundational biodiversity information. In general taxonomists in South Africa are productive and are not limited by financial and infrastructural resources. However, there are still vast areas of the country that remain under-collected, and many taxa remain under-represented in herbarium collections, which indicate that taxonomists are partially limited by lack of plant material and field observations on live plants for research as well as from which to compile specimen data records for end-users. In addition, the example of research on Ixia over the years (see above) reveals that intense study of one group generates a large amount of information over a long period of time. There are not enough taxonomists generating that level of information because it is clearly not happening for all of the 931 plant genera in South Africa. With approximately 20000 vascular plant species in South Africa and around 40 researching taxonomists (including technicians appointed in non-academic posts), the ratio of number of species to taxonomist is about 500 species to one. The large number of under-collected plant species paints a dire picture of how little is known for a large portion of the South African flora. It can therefore be concluded that more human capacity for taxonomic research in South Africa is urgently required. For now, to maximise the effectiveness of existing human capacity, prioritised activities need to be identified and efforts redirected towards these (Victor et al. 2015).

Many taxonomists living and working outside of South Africa have made significant contributions to better understanding the taxonomy of the country's flora. A large number of these taxonomists originate from South Africa and have emigrated recently (ca. 30-50 since 1970), having found employment abroad. Although some continue to conduct taxonomic research on the South African flora and make valuable contributions, this 'brain drain' has undoubtedly had a significant negative impact on plant taxonomic capacity. Other taxonomists contributing from abroad have developed an interest in the flora of the country and furthered knowledge of many taxonomically problematic groups (e.g. Aizoaceae) immeasurably. A register of taxonomists detailing families and/or genera in which they are conducting taxonomic research and country of residence, is provided on the SANBI website (accessible on the link 'Register of taxonomic research' at http://www.sanbi.org/biodiversity-science/foundations-biodiversity/biosystematics-collections/ biosystematics-strategies) as a way of stimulating further interest amongst taxonomists abroad. In addition it serves to coordinate taxonomic research of South Africa's flora on an international level.

A future potential problem for plant taxonomic capacity in South Africa is addressing employment equity targets. As shown in Table 1, not all universities have the capacity to offer post-graduate training in plant taxonomy, whereas some universities have two or even three taxonomists. The lack of capacity for postgraduate students to study taxonomy at the traditionally black universities is a severe impediment to successful transformation of the workforce in South Africa. More universities could undertake postgraduate training of students in taxonomy with external assistance in the form of a taxonomist co-supervisor from SANBI or another university. SANBI has at least 12 senior plant taxonomic researchers who have the ability to co-supervise research projects, but only four are currently involved in this activity. Bursaries offered to students at universities that currently do not have capacity to supervise postgraduate studies in taxonomy could stimulate the interest in this field amongst previously disadvantaged population groups. A solution to this would be for SANBI to more actively promote collaboration with these universities to offer skills for co-supervising postgraduate students, and facilitate (or offer) bursaries for this purpose, especially targeting universities currently without taxonomists. However with only about 40 positions for plant taxonomic researchers in the country, there is limited opportunity for employment and therefore the number of bursaries offered should be calculated carefully to ensure a steady supply for the availability of posts. To provide a choice of quality taxonomists the pool of candidates needs to be competitive, therefore it is essential to train more taxonomists than posts being or becoming available. Because of the specialist nature of taxonomy, which limits career opportunities, taxonomists need to have skills in other fields as a back-up so that they can find careers in for example environmental consulting or conservation, two fields in which trained taxonomists have successfully found employment in South Africa.

An alternative solution to providing future capacity for taxonomic research is for scientists to mentor interested and talented support staff employed in technical positions in herbaria, provided such candidates have an interest 
in, and aptitude for, taxonomic research. At least 11 senior SANBI plant taxonomists are actively mentoring junior scientists, graduates conducting internships or technicians, or have done so in the past five years. Many staff members employed by SANBI, frequently as junior taxonomists, enrol for postgraduate studies in taxonomy, which contributes to the development of institutional taxonomic expertise, in association with university and in-house experts leading the studies. SANBI also offers postdoctoral fellowships, of which one has been assigned to taxonomy in 2014 and has not yet been successfully filled because of the lack of graduates with $\mathrm{PhD}$ degrees available in South Africa. Postdoctoral fellowships also exist on occasion for taxonomy at some universities, but these mostly concentrate on phylogenetic work. These posts are essential to prevent loss of the investment into plant taxonomy and to facilitate the further career development of graduates. Early-career postdoctoral researchers can play a crucial role in advancing the scholarly mission of the host institution by bringing in new thinking and theories, as well as new methodologies. In a South African context postdoctoral researchers should have a responsibility to collaborate with and possibly mentor both junior staff as well as senior colleagues.

Traditionally black universities urgently need to create taxonomy posts so that equity can be redressed. In the meantime it would be beneficial for SANBI to produce more text-book type resources (for example Victor et al. 2004; Koekemoer et al. 2015), where the need exists, so that universities that do not employ taxonomists can still offer the course in a suitably stimulating manner so as to captivate potentially interested taxonomists. SANBI taxonomists have a history of offering training courses in aspects of taxonomy (especially identification of certain plant groups) to interested members of the public, including students, which has the benefits of creating awareness of and stimulating interest in taxonomy. These courses should be additionally promoted amongst botany students at traditionally black universities.

Although the conclusions reached by Von Staden et al. (2013) that taxonomic output in terms of 'revisions' has declined is supported, this cannot be extrapolated to taxonomic research output as a whole but rather to changes in emphasis of research topic. The output by taxonomic researchers in terms of numbers of papers published in ISI-rated journals shows that there is potential capacity to conduct and publish taxonomic research, although much of the research output effort is not spent on taxonomic research. The needs of most end-users are for information of a microtaxonomic nature, but molecular phylogenetic work often supplies information of a macrotaxonomic nature. Using advanced modern analytical techniques to create phylogenies is useful, and indeed often necessary to resolve difficult taxonomic groupings, such as clarifying delimitation of genera. In the past, certain authors claimed that advances in molecular biology and phylogenetic reconstruction were driving taxonomic research to the detriment of 'traditional' taxonomy based on morphological studies (Wortley et al. 2002). It is therefore important not to overemphasise phylogenetic studies at the expense of alpha-taxonomy, but rather support comprehensive taxonomic revisions making use of datasets from other sources (including molecular) where necessary. It should, however, be noted that classifications produced by phylogenetic school of classification are, in contrast to those of the evolutionary school, often less informative to end-users of plant names (e.g. Van Wyk 2007).

Fragmentation of publications into units describing new taxa or revising small sections of a genus enables the information to be available for use in checklists and by end-users much faster than working for years to consolidate everything and publish it when the revision is complete. An electronic means of dissemination, such as a single-portal online Flora, would solve the problem of fragmented information and enable all published literature to be available in a consolidated source. Taxonomic research should focus efforts on prioritised genera or even subdivisions of genera to uncover undescribed species, which can only be determined through comprehensive investigation. As is often the case globally, consolidation of information into Flora-type products can be done concurrently or after the primary research is conducted and published.

There appears to be a split between taxonomists doing molecular phylogenetic work (mainly at universities; supported by excellent laboratory facilities) and those doing more traditional alpha-taxonomy (mainly at SANBI; supported by excellent herbarium collections), and possibly not enough collaboration exists to unite those two ends of the spectrum. Fostering collaboration to ensure that phylogenetic work is not the end product but rather, is incorporated into revisions, would be of great benefit to taxonomic research products, because although end users do not directly require the results of macrotaxonomic studies, it is still a vital component of research. Qualifying scientists at SANBI are encouraged to become research associates at universities as one way to improve and expand collaboration between scientists who follow a more 'traditional' alpha-taxonomic approach and those who more easily use and incorporate molecular phylogenetic methodologies in their research. Likewise, scientists at tertiary institutions and elsewhere with access to molecular facilities are encouraged to forge partnerships with those taxonomists at SANBI who are well-versed in plant revisionary studies. Where practicable, this way of encouraging closer alliances between longestablished and more modern research approaches will be increasingly emphasised in future as a way to strengthen 
inter-institutional and inter-personal collaboration. An added incentive for SANBI researchers to follow this approach is the possibility of indirectly benefitting from government subsidy paid to universities, museums and similar institutions for peer-reviewed material published in qualifying science media. Such fund-sharing has the potential to expand the research budget allocation of both SANBI and university researchers.

Even if the human capacity to conduct plant taxonomic research in South Africa was doubled, there would still be work for taxonomists to do. The need for more taxonomists can clearly be justified but may not be prioritised in a country that already has such shortages of capacity in pre-primary, primary, secondary and tertiary education and social services, such as an effective police force, for example. Therefore aside from lobbying for more jobs to be created, there is an urgent need to utilise available resources (human and other) effectively, and implement a strategy to ensure that priority activities are conducted.

\section{Acknowledgements}

We are grateful to Ms Hannelie Snyman for providing information for conducting the analyses, and to the staff of Biodiversity Information Management and Planning, SANBI, for producing the map in Fig. 2.

\section{References}

Arnold, T.H. \& De Wet, B.C. (Eds.) (1993) Plants of southern Africa: names and distribution. Memoirs of the Botanical Survey of South Africa 62: 1-825.

Baker, J.G. (1896) Irideae. In: Thiselton-Dyer, W.T. (Ed.) Flora capensis VI (Haemodoraceae to Liliaceae). L. Reeve \& Co., London, pp $7-171$.

Bartling, F.G. \& Wendland, H.L. (1824) Diosmeae: descriptae et illustratae. Vandenhoeck \& Ruprecht, Göttingen, 214 pp.

Bredenkamp, C.L. \& Smith, G.F. (2008) Botanical research in South Africa: A questionnaire assessment of opinions of South African botanists. South African Journal of Science 104: 97-100.

Chesselet, P., Mössmer, M. \& Smith, G.F. (1995) Research priorities in the succulent plant family Mesembryanthemaceae Fenzl. South African Journal of Science 91: 197-209.

De Vos, M.P. (1999) Ixia. In: Leistner, O.A. (Ed.) Flora of southern Africa 7 Iridaceae part 2: Ixioideae, fascicle 1: Ixieae. National Botanical Institute, Pretoria, pp. 3-87.

Du Plessis, E. (1985) Taxonomy in the Republic of South Africa. Unpublished report to the National Committee for the International Union of Biological Sciences. CSIR, Pretoria.

Germishuizen, G., Meyer, N.L., Steenkamp, Y. \& Keith, M. (Eds.) (2006) A checklist of South African plants. Southern African Botanical Diversity Network Report 41. SABONET, Pretoria.

Goldblatt, P. \& Manning, J.C. (1993) Ixia acaulis, a new acaulescent species of Iridaceae-Ixioideae from the Knersvlakte, Namaqualand, South Africa. Novon 3: 148-153. http://dx.doi.org/10.2307/3391523

Goldblatt, P. \& Manning, J.C. (1999) New species of Sparaxis and Ixia (Iridaceae: Ixioideae) from Western Cape, South Africa, and taxonomic notes on Ixia and Gladiolus. Bothalia 29: 59-63. http://dx.doi.org/10.4102/abc.v29i1.571

Goldblatt, P. \& Manning, J.C. (2004) New species of Ixia (Crocoideae) and Moraea (Iridoideae), and taxonomic notes on some other African Iridaceae. Novon 14: 288-298.

Goldblatt, P. \& Manning, J.C. (2008) Systematics of the southern African genus Ixia (Iridaceae). 2. The filiform-leaved I. capillaris complex. Bothalia 38: 115-124.

http://dx.doi.org/10.4102/abc.v38i2.276

Goldblatt, P. \& Manning, J.C. (2010) Notes on African plants: Iridaceae. Reappraisal of Ixia maculata with I. calendulacea sp. nov., and an earlier name for I. lutea. Bothalia 40: 59-63.

Goldblatt, P. \& Manning, J.C. (2011) Systematics of the southern African genus Ixia (Iridaceae): 3. Sections Hyalis and Morphixia.

Bothalia 41: 83-134.

http://dx.doi.org/10.4102/abc.v41i1.35

Goldblatt, P. \& Manning, J.C. (2012a) Systematics of the southern African genus Ixia (Iridaceae: Crocoideae): 4. Revision of sect. Dichone. 


\section{Bothalia 42: 87-110.}

http://dx.doi.org/10.4102/abc.v42i2.11

Goldblatt, P. \& Manning, J.C. (2012b) New species and subspecies of Babiana, Hesperantha and Ixia (Crocoideae) from southern Africa, range extensions, and morphological and nomenclatural notes on Babiana and Geissorhiza. Bothalia 42: 137-145. http://dx.doi.org/10.4102/abc.v42i2.13

Goldblatt, P., Manning, J.C. \& Helme, N.H. (2015) New species of Ixia (Iridaceae: Crocoideae) from western South Africa, with a revised circumscription of I. cedarmontana and some important range extensions. South African Journal of Botany 98: 108-113. http://dx.doi.org/10.1016/j.sajb.2015.02.010

Herbert, D.G., Smith, G.F., Hamer, M.L. \& Scholtz, C.H. (2001) Taxonomy and systematics in South Africa: vital research facing a crisis in capacity and resources. (Submitted on 15 May 2001). Unpublished report to the National Research Foundation and the Department of Arts, Culture, Science and Technology, Pretoria, 17 pp.

Herman, P.P.J. \& Koekemoer, M. (2014) Two new species of Callilepis (Asteraceae) from southern Africa with corymbose inflorescences. Phytotaxa 183 (4): 254-262.

http://dx.doi.org/10.11646/phytotaxa.183.4.4

Ker Gawler, J.B. (1803) Iridaceae Geissorhiza. Botanical Magazine 18: 672.

Koch, K.H.E. (1854) Index seminum. Typis C. Feisteri, Berlin, 9 pp.

Koekemoer, M., Steyn, H.M. \& Bester, S.P. (2015) Guide to plant families of southern Africa, 3rd edn. Strelitzia 31. South African National Biodiversity Institute, Pretoria, 300 pp.

Kupicha, F.K. (1984) Studies on African Asclepiadaceae. Kew Bulletin 38: 599-672. http://dx.doi.org/10.2307/4108575

Krell, F.-K. (2002) Why impact factors don't work for taxonomy. Nature 415: 957. http://dx.doi.org/10.1038/415957a

Leistner, O.A. (Ed.) (2000) Seed plants of southern Africa: families and genera. Strelitzia 10, National Botanical Institute, Pretoria, 775 pp. Lewis, G.J. (1962) South African Iridaceae. The genus Ixia. Journal of South African Botany 28: 45-195.

Linnaeus, C. (1753) Ixia. Species plantarum 1. L. Salvius, Stockholm, 560 pp.

Manning, J.C. \& Goldblatt, P. (2006) New species of Iridaceae from the Hantam-Roggeveld Centre of Endemism, and the Bokkeveld, Northern Cape, South Africa. Bothalia 36: 139-146.

http://dx.doi.org/10.4102/abc.v36i2.352

Manning, J. \& Goldblatt, P. (2013) Plants of the Greater Cape Floristic Region 1: the Core Cape flora. Strelitzia 29, SANBI, Pretoria, 853 pp.

Meyer, E.H.F. (1837) Schizoglossum. Commentariorum de plantis Africae Australioris. Leopoldum Voss, Lipsiae [Leipzig], 326 pp.

Retief, E. \& Herman, P.P.J. (1997) Plants of the northern provinces of South Africa: keys and diagnostic characters. Strelitzia 6, National Botanical Institute, Pretoria, $681 \mathrm{pp.}$

Smith, G.F., Van Wyk, A.E., Johnson, L.A.S. \& Van Wyk, B-E. (1996) Southern African plant systematics: needs, priorities and actions. South African Journal of Science 92: 314-320.

Smith, G.F. \& Willis, C.K. (1997) Index herbariorum: southern African supplement. Southern African Botanical Diversity Network Report No. 2. SABONET, Pretoria. 55 pp.

Smith, G.F. \& Willis, C.K. (1999) Index herbariorum: southern African supplement, 2nd edn. Southern African Botanical Diversity Network Report No. 8. SABONET, Pretoria, 181 pp.

Smith, G.F., Willis, C.K. \& Mössmer, M. (1999) Southern African herbarium needs assessment. In: Southern African Botanical Diversity Network Report No. 6. SABONET, Pretoria, 88 pp.

Snijman, D.A. (Ed.) (2013) Plants of the Greater Cape Floristic Region 2: the Extra Cape flora. Strelitzia 30: 1-544.

Thiers, B. (2015) [continuously updated] Index Herbariorum: A global directory of public herbaria and associated staff. New York Botanical Garden's Virtual Herbarium. Available from: http://sweetgum.nybg.org/science/ih/ (accessed 16 November 2015)

Van Wyk, B. \& Malan, S. (1997) Field guide to the wild flowers of the Highveld. Struik, Cape Town, 352 pp.

Van Wyk, A.E. (2007) The end justifies the means. Taxon 56: 645-648. http://dx.doi.org/10.2307/25065849

Van Wyk, B-E., Van Oudtshoorn, B. \& Gericke, N. (2009) Medicinal plants of South Africa. Briza Publications, Pretoria, 336 pp.

Van Wyk, B. \& Van Wyk, P. (2013) Field guide to trees of southern Africa, $2^{\text {nd }}$ edn. Struik Nature, Cape Town, 732 pp.

Victor, J.E., Koekemoer, M., Fish, L., Smithies, S. \& Mössmer, M. (2004) Herbarium essentials. Southern African Botanical Diversity Network Report 25. SABONET, Pretoria, 93 pp.

Victor, J.E., Smith, G.F., Turland, N.J., Le Roux, M., Paton, A., Figueiredo, E., Crouch, N.R., Van Wyk, A.E., Filer, D. \& Van Wyk, E. (2013) Creating an online world Flora by 2020: a perspective from South Africa. Biodiversity \& Conservation 23: $251-263$. http://dx.doi.org/10.1007/s10531-013-0595-0

Victor, J.E., Smith, G.F. \& Van Wyk, A.E. (2015) A method for establishing taxonomic research priorities in a megadiverse country. 
Phytotaxa 203 (1): 55-62.

http://dx.doi.org/10.11646/phytotaxa.203.1.5

Von Staden, L., Raimondo, D. \& Dayaram, A. (2013) Taxonomic research priorities for the conservation of the South African flora. South African Journal of Science 109 (3/4): 1-10.

http://dx.doi.org/10.1590/sajs.2013/1182

Willdenow, K.W. (1809) Enumeration plantarum Horti Regii Botanici Berolinensis. In Taberna Libraria Scholae Realis, Berlin, 1145 pp.

Wortley, A.H., Bennett, J.R. \& Scotland, R.W. (2002) Taxonomy and phylogeny reconstruction: two distinct research agendas in systematics. Edinburgh Journal of Botany 59: 335-349.

http://dx.doi.org/10.1017/S0960428602000203 